\title{
Prenatal Diagnosis of Ebstein Anomaly in a Centre with Limited Resources: A Potential Pitfall
}

\author{
Ramush Bejiqi ${ }^{1,2,3}$, Ragip Retkoceri ${ }^{3}$, Hana Bejiqi ${ }^{4}$, Aferdita Mustafa $^{3}$, Arlinda Maloku ${ }^{4}$, Rinor Bejiqi ${ }^{3 *}$ \\ ${ }^{1}$ Texas Health Science Center, San Antonio, Texas, USA; ${ }^{2}$ Medical School, University of Gjakova "Fehmi Agani”, Gjakova, \\ Kosovo; ${ }^{3}$ University Clinical Center of Kosovo, Prishtina, Kosovo; ${ }^{4}$ Main Center of Family Medicine, Prishtina, Kosovo
}

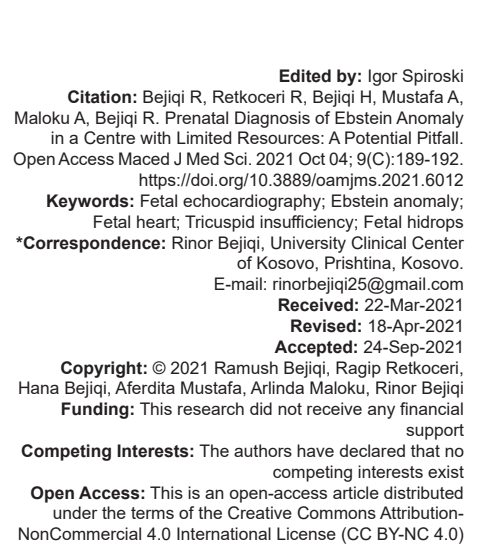

Introduction

Ebstein anomaly is an uncommon congenital abnormality with a prevalence of $0.2-0.5 \%$ of all cardiac malformations. It can appear at any age, from fetal life to adulthood, with a highly variable clinical course. In the fetus and neonate, a targeted echocardiogram has been proven to be reliable in differentiating the variants of Ebstein anomaly [1]. However, because targeted fetal echocardiography cannot be used routinely for all obstetric patients, the ability to recognize Ebstein anomaly from a routine prenatal obstetric sonographic examination is important. The 4-chamber view of the heart, a component of the American Institute of Ultrasound in Medicine guidelines for fetal structural evaluations, is most helpful for the detection of many congenital heart defects, including Ebstein anomaly. The 4-chamber view, however, does have limitations in the diagnosis of certain cardiac malformations [2]. We here present a rare case of a fetus with severe form of Ebstein anomaly, diagnosed by fetal echocardiography after an initial routine obstetric sonogram, and discuss the diagnostic considerations in such patients.

\section{Case Report}

A 26-year-old gravida 1 , para 0 woman was referred to our tertiary center at 20.4 weeks of gestation with a suspected cardiac anomaly. Her previous medical history was unremarkable, and she had no family history of congenital malformation. She had no known history of teratogen exposure at any time during pregnancy. The fetus had appropriate biometrical dimensions and appeared morphologically normal. Quad tests and other prenatal laboratory findings were within normal ranges. A fetal echocardiography was performed and the four-chamber view of the heart revealed cardiomegaly with a right heart side dilatation and without definite contractility. There were evidence of discernible tricuspid leaflets (Figure 1a-c), indicating the downward displacement of a tricuspid valve structure. Color Doppler imaging showed forward and backward flows from the right atrium to the right ventricle with evidence of huge tricuspid regurgitation (Figures 1d and e and 2). Because the tricuspid valve structure was completely incompetent and also because there were communicating flows between the right atrium and right ventricle, the fetus was thought to have 


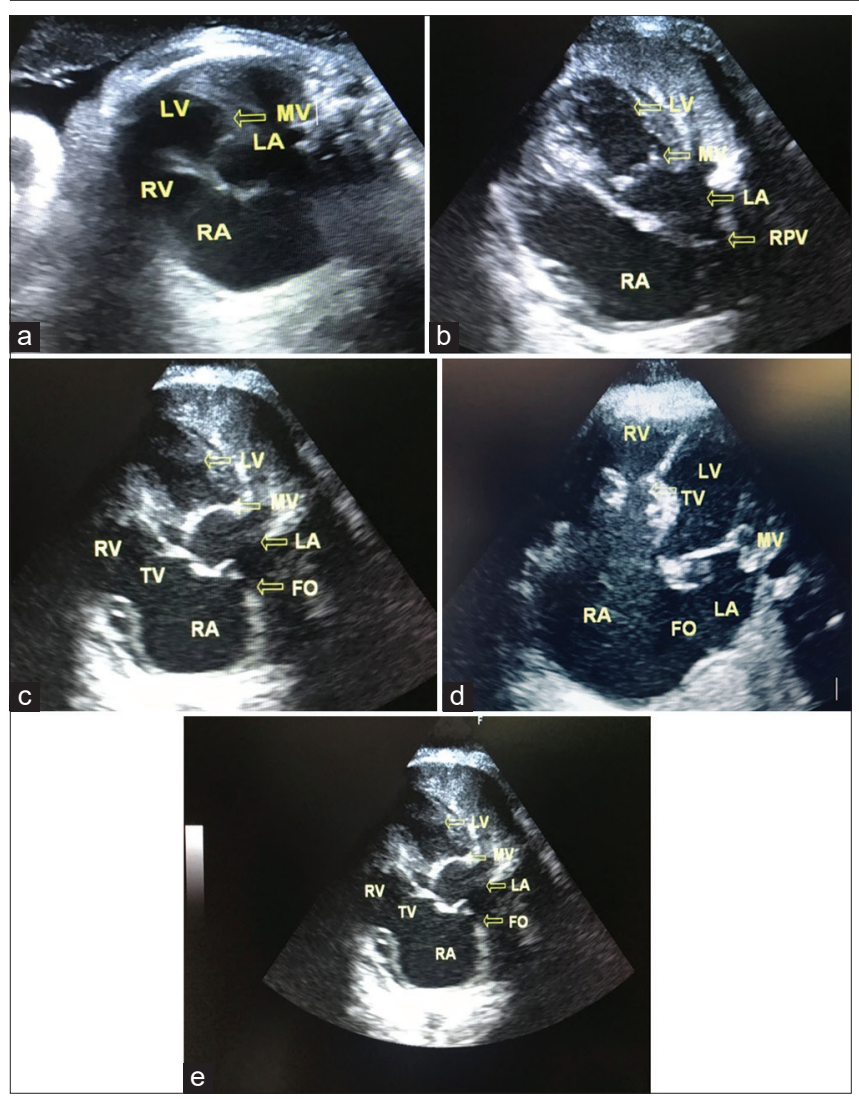

Figure 1: (a-e) Four-chamber view of the heart in the study patient showing the dilatation of the right atrium, with reduction of the right ventricle. (LV: Left ventricle, MV: Mitral valve, LA: Left atrium, RV: Right ventricle, RA: Right atrium, FO: Foramen ovale, TV: Tricuspid valve)

a severe form of Ebstein anomaly. Morphological and functional pulmonary hypoplasia was also associated. No other abnormalities were detected.

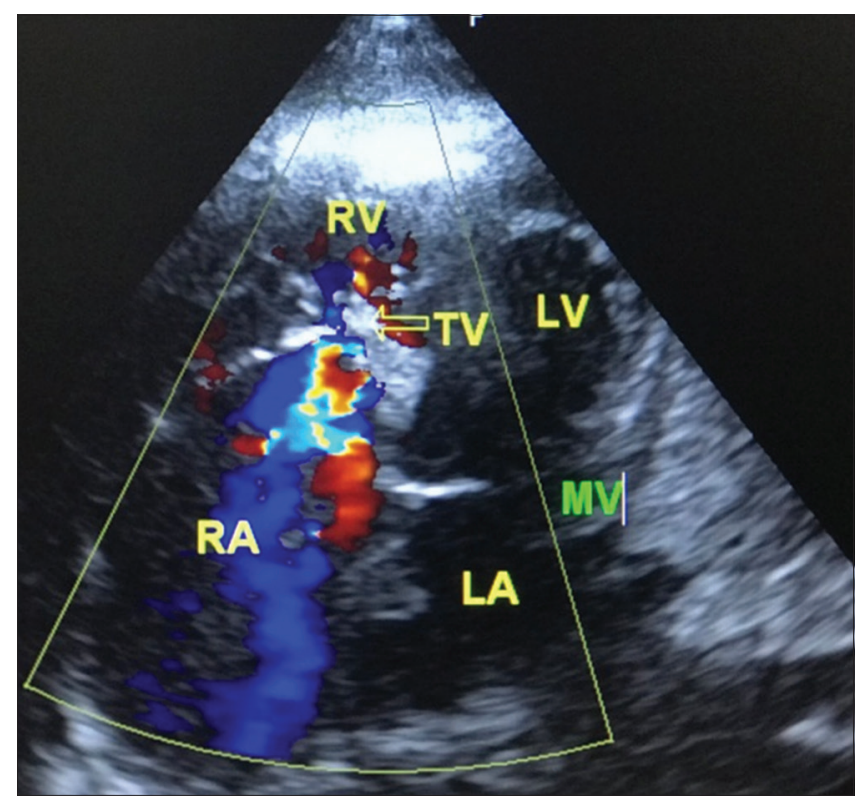

Figure 2: Color Doppler imaging showing a flow from the right restricted ventricle to the right atrium. ( $L V$ - left ventricle, $M V$ - mitral valve, $L A$ - left atrium, $R V$ - right ventricle, $R A$ - right atrium, FO - foramen ovale, TV - tricuspid valve)

Following the counseling on the postnatal outcomes, the parents decided to continue the pregnancy and did not want to undergo fetal karyotyping and other laboratory analysis. Weekly subsequent serial echocardiographic examinations showed no demonstrable changes. A follow-up evaluation at 37 weeks of gestation revealed initial newly developed skin edemas, small pleural effusion, and ascites suggestive of fetal hydrops. She was admitted at the Obstetric Clinic and during the next period, there were no increase signs of heart failure. Normal delivery at 39 weeks of gestation was done and a female neonate of $3200 \mathrm{~g}$ was delivered. Baby was cyanotic with an Apgar score of 4 and 5 at 1 and 5 min, respectively, and $\mathrm{a} \mathrm{SaO}_{2}$ level of $50 \%$. An initial transthoracic echocardiography indicated and findings confirmed the initial diagnosis. Transthoracic echocardiography showed an Ebstein anomaly type-D, stenotic form with almost full atrialization of the right ventricle leaving only a very small functional portion of this ventricle (Video 1 and 2). Furthermore, echocardiography showed a big hole at the atrial level with bidirectional flow, mostly right to left, and hypoplastic pulmonary artery (Video 3). Chest X-ray showed extreme cardiomegaly which fills the thoracic space and signs of pulmonary congestion. Immediately after birth, the child has developed signs of respiratory distress, cardiac insufficiency, and central cyanosis, while gas analysis has shown signs of severe respiratory acidosis, and the child was intubated. Despite medical treatment of the heart failure with diuretics, inotropes and vasodilatators, unfortunately, the baby died on day 3 after delivery because of continuous respiratory distress and heart failure.

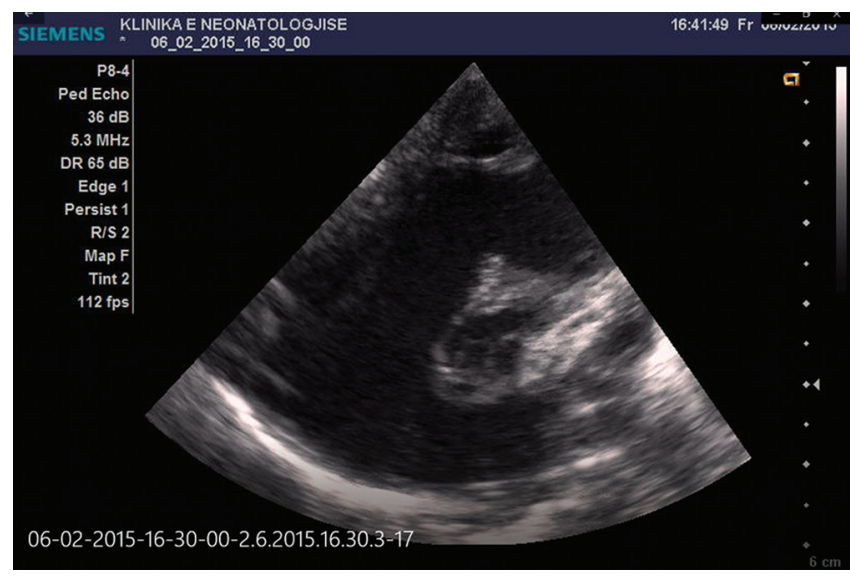

Video 1: ???

\section{Discussion}

Ebstein anomaly is a rare tricuspid valve anomaly occurring in about 1-5/200,000 live births and accounting for less than $1 \%$ of all congenital heart diseases. The anomaly is characterized by a downward displacement of the tricuspid valve into the right ventricle because the anomalous leaflets basal attachment [1]. The pathophysiology varies with the 




Video 2: ???

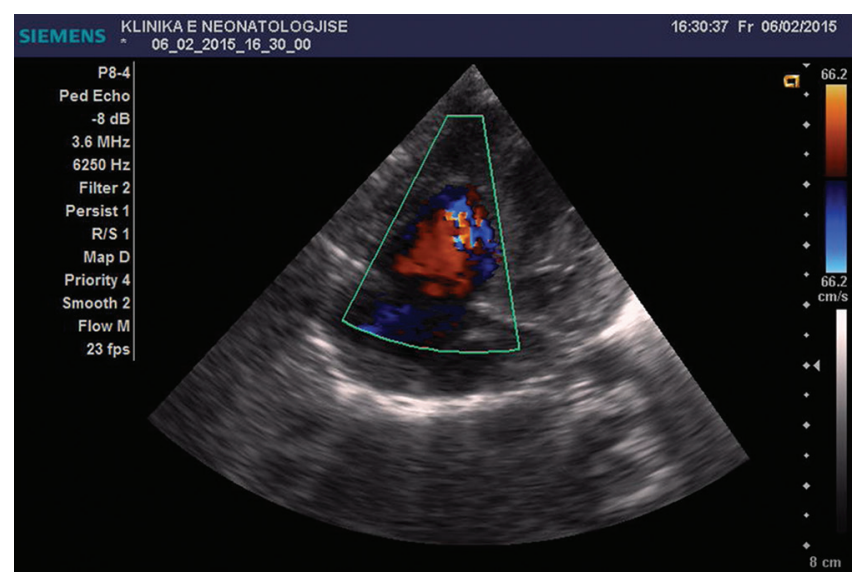

Video 3: ???

degree of valvular malfunction, the size, and contractility of the right ventricle and the presence of obstruction within the right ventricular outflow tract. Some fetuses with Ebstein's anomaly have concurrent severe cardiac function impairment, which results in fetal or early postnatal heart failure. Most of these fetuses are inevitably terminally ill [3].

To the best of our knowledge, our report is the very rare case which describes the prenatal echocardiographic diagnosis of a postnatally confirmed type-D Ebstein anomaly. In contrast to earlier reports that the majority of neonatal Ebstein anomalies are not diagnosed in the prenatal period, the recent reports suggested that there is increased number of prenatally diagnosis of this condition. Numbers of babies in these series, died immediately after birth, is very low and mostly includes Ebstein anomaly type-D. This anomaly shows various ultrasonographic manifestations, thus making sometimes the prenatal diagnosis difficult. In our current case, the tricuspid valves were completely nonvisible and did not demonstrate the typical findings of Ebstein anomaly such as tricuspid regurgitation and right atrial enlargement in the prenatal period [4].

Echocardiography during the fetal life can reveal malformations with tricuspid valve incompetence and they should be searched when the right atrial is enlarged. Although the ultrasonic appearance of typical
Ebstein anomaly is becoming increasingly familiar, the rare type should also be considered, thereby increasing the current knowledge and providing additional clinical information to improve the diagnostic rate of Ebstein anomaly using ultrasound techniques [5].

Targeted fetal echocardiography is a reliable technique for diagnosing Ebstein anomaly. Typical features of this disease are recognized as cardiomegaly, apical displacement of the insertion of the tricuspid septal leaflet $\left(>8 \mathrm{~mm} / \mathrm{m}^{2}\right.$ body surface area) with a redundant elongated anterior tricuspid leaflet, right atrial enlargement which results from dilatation of the atrialized portion of the right ventricle, and marked tricuspid regurgitation [5], [6]. Arrhythmia and fetal hydrops are also possible fetal manifestations of Ebstein anomaly [4]. Ebstein anomaly can be classified by its anatomical presentation. Type $A$ is designated as an adherence of the septal and posterior leaflets without a restriction of the functional right ventricle volume; type $B$ means that the right ventricle has atrialized with a normal anterior leaflet; type $\mathrm{C}$ refers to cases with a stenotic anterior leaflet; and type $D$ cases manifest with an almost complete atrialization of the ventricle, with the exception of a small infundibular component. Although the precise prevalence of each type of Ebstein anomaly has not been investigated, it is assumed that type $\mathrm{D}$ accounts for $3.5 \%$ to $8 \%$ of cases and also that the prenatal diagnosis of type-D is rarer. In type-D cases, all of the leaflet tissue, even the anterior parts, is attached to the right ventricular wall [7], [8]. When the attachment of the tricuspid valve leaflets is extremely distal, it is difficult to detect because it may be confused with the papillary muscle in the right ventricle. In such cases, the right atrium and ventricle may mimic a single large sac, which results in a misdiagnosis if the examiners fail to identify the small infundibular ventricular portion. This was why our current cases had been misdiagnosed as an absent tricuspid valve rather than an Ebstein anomaly [8], [9]

The prenatal diagnosis of an Ebstein anomaly will become more important in the future because the outcomes of surgical and conservative management have improved a great deal in the current era [5]. The prognosis for a fetus diagnosed with Ebstein anomaly has been extremely poor in the past with a reported mortality rate as high as $81 \%$. There have also been no clear indications in the past for surgical interventions in critically ill neonatal cases [10]. However, with the gradual improvement in surgical technique and medical management, neonatal mortality has been reported at $7-24 \%$ and neonatal surgical mortality at a decreased rate of 23-27\% [6], [7].

\section{Conclusion}

We think that the prenatal diagnosis of the Ebstein anomaly in routine screening is possible with careful sonographic evaluation. 
Ebstein anomaly should be considered as a possible diagnosis when a tricuspid valve abnormality is suspected prenatally, even if there are no visible tricuspid leaflets. Awareness of several diagnostic pitfalls with careful ultrasonography evaluation can help physicians to reach an accurate prenatal diagnosis in this regard. Perhaps, every effort in the future should be directed to therapeutical measures to avoid heart enlargement and the subsequent pulmonary hypoplasia during the fetal life, improving the prognosis of these cases. Furthermore, this will enable better and more informed prenatal counseling for parents and assist clinicians to adopt multidisciplinary approaches, including the induction of high-risk delivery, surgical intervention planning, and perinatal intensive care. Fetal echocardiography has been the first choice for diagnosing Ebstein anomaly because this technique is not only accurate, rapid, simple, and inexpensive but also has a high diagnostic value.

\section{Ethical Approval}

This report was approved by the Ethical Committee at University Clinical Center of Kosovo in Prishtina, Number 1704, date 27 of November 2019, and both parents provided written informed consent.

\section{Acknowledgments}

The authors wish to thank the family involved in this study for their collaboration and Prof Dr Orhan Uzun in the editing and critical approval of this manuscript.

\section{Author Contributions}

All the authors have accepted responsibility for the entire content of this submitted manuscript and approved submission.

Postnatal echocardiogram showing an almost completely atrialized right ventricle with only a small outlet portion operating as a functional right ventricle and a severe downward displacement of the tricuspid valve leaflet insertion site (Video 1). The right ventricular outlet view also showing a very small functional right ventricle and severe tricuspid regurgitation on color Doppler (Video 2 and 3).

\section{References}

1. Anderson KR, Zuberbuhler JR, Anderson RH, Becker AE, Lie JT. Morphologic spectrum of Ebstein's anomaly of the heart: A review. Mayo Clin Proc. 1979;54(3):174-80.

PMid:431123

2. Tongsong $\mathrm{T}$, Chanprapaph $\mathrm{P}$, Khunamornpong $\mathrm{S}$, Sirichotiyakul S. Sonographic features of Ebstein anomaly associated with hydrops fetalis: A report of two cases. J Clin Ultrasound. 2005;33(3):149-53. http://doi.org/10.1002/jcu.20102 PMID: 15756659

3. DearaniJA, DanielsonGK. Congenitalheartsurgerynomenclature and database project: Ebstein's anomaly and tricuspid valve disease. Ann Thorac Surg. 2000;69(4 Suppl):S106-17. http:// doi.org/10.1016/s0003-4975(99)01265-5

PMid:10798422

4. Cha MY, Won HS, Lee MY, Woo KH, Shim JY. An unusua ultrasonographic manifestation of a fetal Ebstein anomaly. Obstet Gynecol Sci. 2014; 57(6):530-3. http://doi.org/10.5468/ ogs.2014.57.6.530 PMid:25469344

5. McElhinney BD, Salvin WJ, Colan DS, Thiagarajan R, et al. Improving outcomes in fetus and neonates with congenital displacement (Ebstein'Malformation) or dysplasia of the tricuspid valve. Am J Cardiol. 2005;96(4):582-6. http://doi. org/10.1016/j.amjcard.2005.04.024

PMid:16098316

6. Donofrio M, Moon-Grady A, Hornberger L, Copel JA Sklansky MS, Abuhamad A, et al. Diagnosis and treatment of fetal cardiac disease: A scientific statement from the American heart association. Circulation. 2014;129(21):2183-242. http:// doi.org/10.1161/01.cir.0000437597.44550.5d

PMid:24763516

7. International SO, Carvalho JS, Allan LD, Chaoui R, Copel JA DeVore GR, et al. ISUOG Practice Guidelines (updated): Sonographic screening examination of the fetal heart. Ultrasound Obstet Gynecol. 2013;41(3):348-59. http://doi. org/10.1002/uog.12403

PMid:23460196

8. Zimmer EZ, Blazer S, Lorber A, Solt I, Egenburg S, Bronshtein M Fetal Ebstein's anomaly: Early and late appearance. Prenat Diagn. 2012;32(3):228-33. http://doi.org/10.1002/pd.2935 PMid:22430719

9. Negoi RI, Ispas AT, Ghiorghiu I, Filipoiu F, Negoi I, Hostiuc M, et al. Complex Ebstein's malformation: Defining preoperative cardiac anatomy and function. J Card Surg 2013;28(1):70-81. http://doi.org/10.1111/jocs.12032 PMid:23330581

10. Lin $Y N$, Wang $Y Q, Y u ~ Y$, Cao $Q$, Wang F, Chen SY. Left ventricular noncompaction cardiomyopathy: A case report and literature review Int J Clin Exp Med. 2014;7(12):5130-3.

PMid:25664015 